Fourth International Conference on Sustainable Construction Materials and Technologies http://www.claisse.info/Proceedings.htm

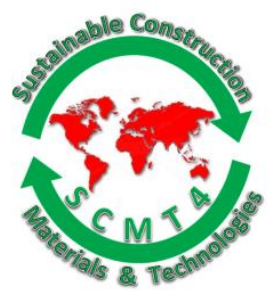

SCMT4

Las Vegas, USA, August 7-11, 2016

\title{
Damage Estimation of Buckle Plate Slab Under Fatigue Test by Elastic Wave Method
}

\author{
Kentaro Ohno ${ }^{1 a}$, Kimitaka Uji ${ }^{1 b}$, Atsushi Ueno ${ }^{1 c}$, and Mikio Sekiguchi² \\ ${ }^{1}$ Dept. Of Civil and Environmenatl Engineering; Tokyo Metropolitan University, 1-1 Minamiosawa, \\ Hachioji, Tokyo,192-0397, Japan. ${ }^{1 a}$ Email: <ohno@tmu.ac.jp>, ${ }^{1 b}$ Email: <k.uji@tmu.ac.jp>, \\ ${ }^{1}$ Email: <eagle@tmu.ac.jp>. \\ ${ }^{2}$ Civil Engineering Support and Training Center, Tokyo Metropolitan Government, 1-9-15 Shinsuna, \\ Kotoku, Tokyo, 136-0075, Japan, ${ }^{2}$ Email: <Mikio_Sekiguchi@member.metro.tokyo.jp>.
}

\begin{abstract}
Tokyo Metropolitan Government has drawn up a long-term bridge strategy for long time use of existing bridges. Especially, Kiyosu bridge in Tokyo has been designated as a nationally important cultural property, maintenance of this bridge is in great demand. Buckle plate (BP) slab has been adopted for this bridge. BP slab consists of steel plate and concrete, its characteristic is that steel plate and concrete are not connected structurally. The adopting of BP slab is rare in highway bridges in Japan. Since there is little information about fatigue durability on BP slab, fracture mechanisms and fatigue durability on BP slab have not been clarified yet. In addition, it is important to draw up a maintenance strategy of BP slab.

In this study, wheel load running test was conducted to real-size BP slab specimen to investigate fatigue durability and fracture mechanisms. In the experiment, Acoustic Emission (AE) monitoring and elastic wave method were applied to estimate concrete damage in BP slab. As a result, deterioration process in $\mathrm{BP}$ slab of fatigue test is discussed based on deflection, AE source location and elastic wave velocity of the specimen. In the AE monitoring, AE sources were localized at bottom of the specimen in early cycles of fatigue test because delamination occurred at between concrete and steel plate, and then AE signals due to punching shear cracks were detected with increasing of loading cycle. As for results of the elastic wave method, elastic wave velocity in concrete decreased with increasing of loading cycle, damage degree could be estimated by elastic wave method. Therefore, AE method and elastic wave method are demonstrated as one of the suitable tools for maintenance of the BP slab.
\end{abstract}

\section{INTRODUCTION}

The number of civil infrastructures built more than 50 years ago has been increasing not only in Japan but also the other developed countries. Especially, since reinforced concrete (RC) slabs are subjected to a variety of environmental conditions such as traffic loads, temperature and humidity, it is important to estimate current state of RC slabs. According to Standard Specification for Concrete Structures in Japan, damage degree in RC slab can be estimated based on crack density on the bottom surface of the slab as shown in Figure 1 [JSCE 2010]. In Japan, the Bridge Inspection Manual is notified by Ministry of Land, 
Infrastructure, Transport and Tourism (MLIT) in 2004. The inspection of existing bridge is conducted to each bridge element by visual inspection every five years. Damage degree in RC slab is classified by result of comparing visual inspection with Figure 1. It is important to predict damage in RC slab to draw up the maintenance plan for all bridges before critical damage occurs in bridges.

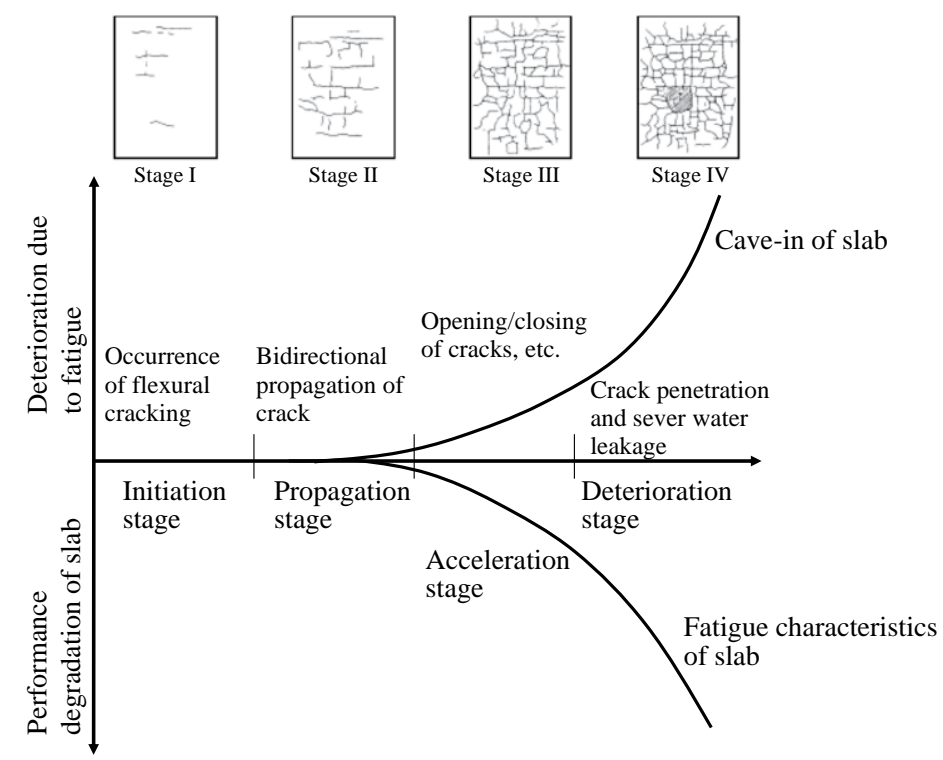

\section{Figure 1. Deterioration process due to fatigue of concrete slab}

Tokyo Metropolitan Government has drawn up a long-term bridge strategy for extending of life in old bridges. Especially, Kiyosu bridge in Tokyo as shown in Figure 2 has been designated as the nationally important cultural properties, thus the maintenance of this bridge is particularly necessary. Buckle plate (BP) slabs have been applied to this bridge. The BP slab consists of steel plate (buckle plate) and concrete, these materials are not connected structurally. Because the amount of information on the fatigue durability of the BP slab is little, fatigue test of BP slab is important for determination of the maintenance plan. In addition, since repair work would be conducted based on inspection result, demand for quantitative estimation method of the current state in a structure is increasing. Besides a regular inspection (visual inspection), nondestructive techniques (NDT) are encouraged to apply to concrete structures. Here, it is well known that acoustic emission (AE) method and impact elastic wave method are powerful tools for defect and crack detection methods by NDT.

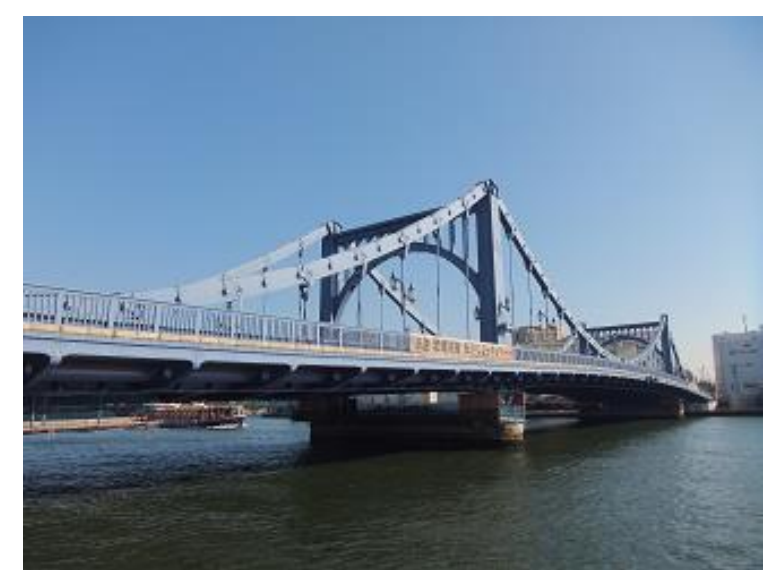

Figure 2. Kiyosu Bridge 
$\mathrm{AE}$ phenomenon is defined as the propagation of elastic wave due to release strain energy, such as a generation of micro crack in material [Ohtsu 1995]. The AE technique has been widely used in concrete member for mechanisms of concrete fracture and estimation of damage degree [Nair and Cai 2010, Ohno and Ohtsu 2010, Behnia et al. 2014]. The AE actives are usually classified into two types of "primary AE" and "secondary AE". The former is associated with crack generation, on the other hand, the latter is signal due to slip motion of existing crack surfaces in a material. These signals could be classified by characteristics of waveform such as average frequency and RA value [JCMS-III B5706 code 2003, Ohtsu 2010, Aggelis et al. 2013]. The advantage of AE technique is that fracture behavior of concrete could be observed in real time under applied load. In addition, the deterioration area is easily estimated by using location procedure of $\mathrm{AE}$ source.

The other useful tool for detection of deteriorated area in concrete is impact elastic wave method. The wave excited by a steel ball or a hammer propagates in concrete and propagated wave is picked up by sensors. In case of damaged concrete, it is known that wave velocity and amplitude of the signal decrease when elastic wave propagates damage area in concrete. Recently, the travel-time tomography technique of elastic wave is often applied to estimate damage area because results of the tomography are easy to be understood not only by NDT engineers but also by people without the relevant technical background [Liu et al. 2014, Shiotani et al. 2009]. In the travel-time tomography, multiple sensors are mounted on the surface of concrete, then elastic wave is excited at each sensor position. The propagated wave is detected at different sensor locations. After that, monitoring area is divided into small elements, wave velocity at each element is determined. The result of the travel-time tomography is illustrated by mapping of the change of velocity in target area.

In this study, wheel load running test was conducted to a real-size BP slab specimen to investigate fatigue durability. In addition, damage degree and deterioration process were monitored by AE method and impact elastic wave method. Since the number of research on adopting of these methods for damage estimation in the BP slab is small, it is thought that results of our experiment are important for maintenance of the BP slab.

\section{EXPERIMENTAL PROCEDURE}

Specimen and Wheel Load Running Test. The specimen was a real size model of Kiyosu bridge's BP slab. This specimen was made to simulate repair work in the future. Figure 3 illustrates specimen geometry, the dimensions of specimen are 1,780 $\mathrm{mm}$ long, 1,800 mm wide and the thickness is changed from $200 \mathrm{~mm}$ at the edge to $276 \mathrm{~mm}$ at the center. Concrete mixture proportions are given in Table 1 . The aggregate used specimen was type II lightweight aggregate, the compressive strength of concrete was $47.5 \mathrm{~N} / \mathrm{mm}^{2}$, and elastic modulus was $17.0 \mathrm{kN} / \mathrm{mm}^{2}$ at 28 days. The SS400 (tensile strength of rolled steels for general structure is $400 \mathrm{~N} / \mathrm{mm}^{2}$ ) was adopted for BP in the slab specimen. The thickness of the BP was $4.5 \mathrm{~mm}$. The studs $(\phi 16 \times 100 \mathrm{~mm})$ were applied to prevent uplift of concrete from BP.

\section{Table 1. Mixture proportion of concrete}

\begin{tabular}{|c|c|c|c|c|c|c|c|c|c|}
\hline \multirow{2}{*}{$\begin{array}{c}\text { Gmax } \\
(\mathrm{mm})\end{array}$} & $\begin{array}{c}\text { S1 } \\
(\mathrm{cm})\end{array}$ & \multirow{2}{*}{$\begin{array}{c}\text { W/C } \\
(\%)\end{array}$} & \multirow{2}{*}{$\begin{array}{c}\text { Air } \\
(\%)\end{array}$} & \multirow{2}{*}{$\begin{array}{c}\text { S/a } \\
(\%)\end{array}$} & & \multicolumn{5}{|c|}{ Unit weight $\left[\mathrm{kg} / \mathrm{m}^{3}\right]$} \\
\cline { 5 - 9 } & & & & & $\mathrm{W}$ & $\mathrm{C}$ & $\mathrm{S}$ & $\mathrm{G}$ & $\mathrm{Ad}$ \\
\hline 15 & 21 & 38.6 & 5.0 & 45.0 & 175 & 453 & 510 & 446 & 6.342 \\
\hline
\end{tabular}

Fatigue test by the wheel load running machine with a rubber tire was conducted at a laboratory as shown in Figure 4. The specimen was simply supported on two shorter edges. Figure 5 shows the loading program for specimen in the test. The experiment was continued until 700 thousands cycles. The experiment was consisted by three steps, 1) wheel load running with AE monitoring, 2) static loading test 
with measurement of deflection at center of the specimen and AE monitoring, 3) impact elastic wave method under non loading condition.

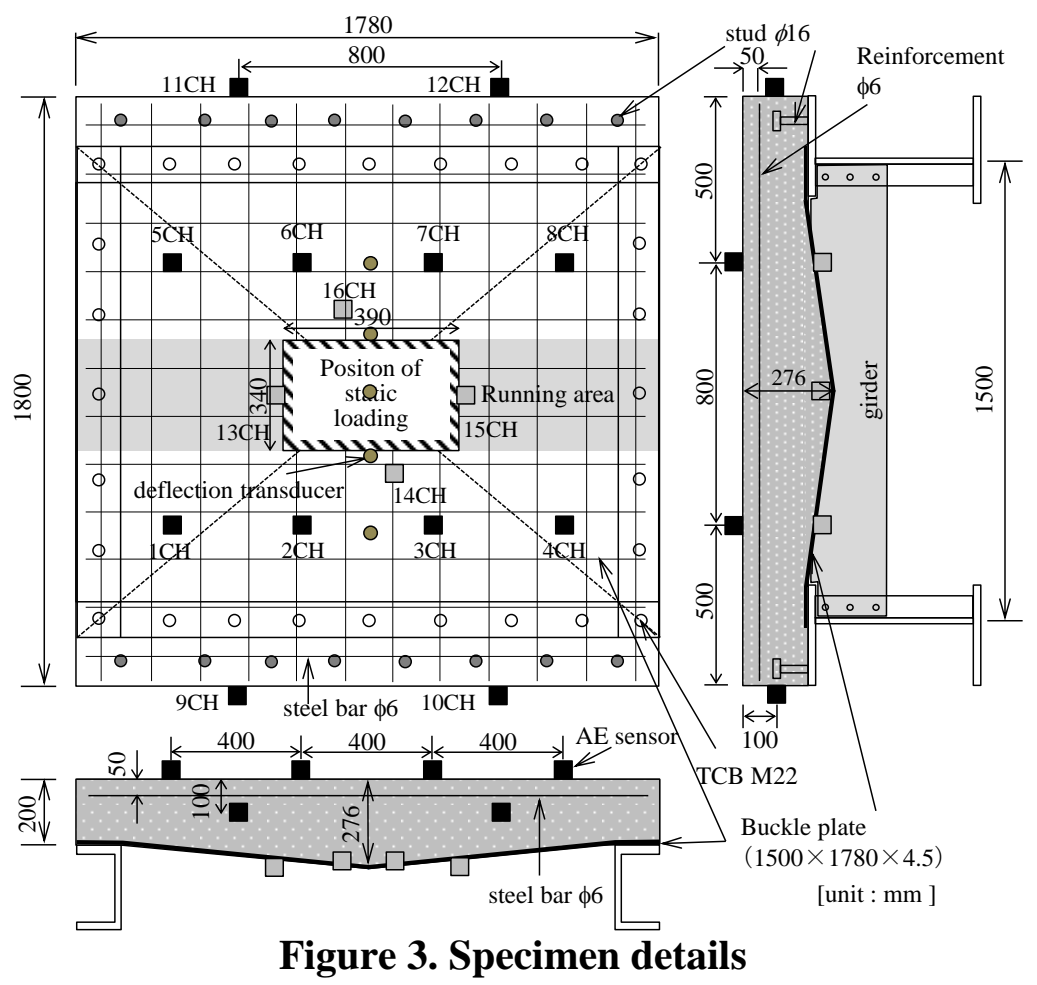

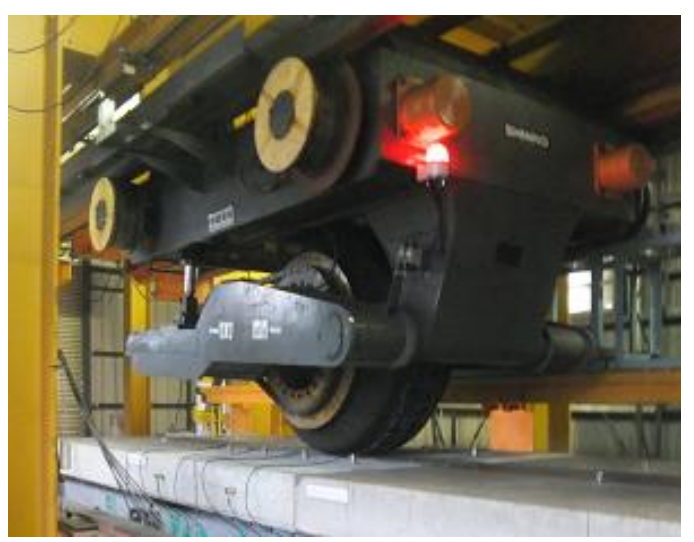

Figure 4. The wheel load running machine

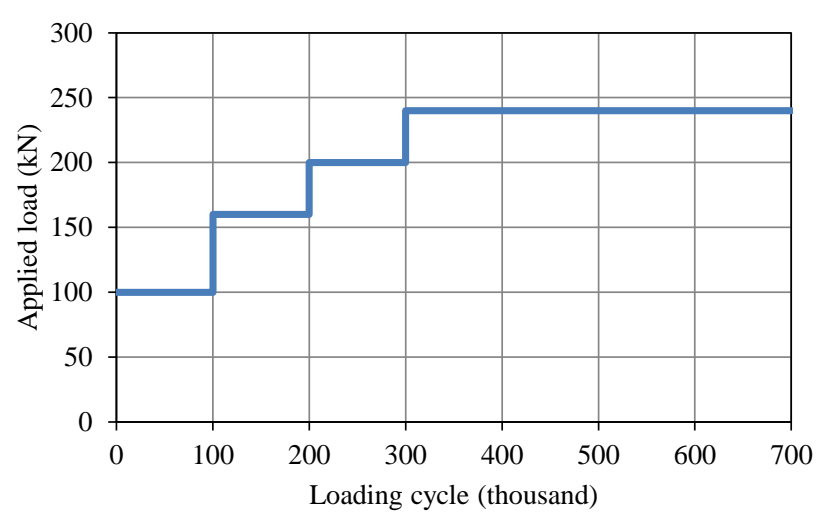

Figure 5. Loading Program

AE Monitoring and Impact Elastic Wave Method. 12 AE sensors were attached to the concrete surface and $4 \mathrm{AE}$ sensors were mounted on the $\mathrm{BP}$ as shown in Figure 3. The resonance frequency of all $\mathrm{AE}$ sensors was $60 \mathrm{kHz}$. AE signals were amplified with $40 \mathrm{~dB}$ gain by pre-amplifier, and then they were recorded by $\mathrm{AE}$ measurement system. In AE monitoring, sampling rate was $1 \mathrm{MHz}$, the threshold level was set to $75 \mathrm{~dB}$ to avoid noise from testing machine during wheel load running test, and $40 \mathrm{~dB}$ of the threshold level was adopted for static loading.

In impact elastic wave method, elastic waves were excited by pencil lead break at each sensor position from $1 \mathrm{CH}$ to $12 \mathrm{CH}$ attached to concrete surface. The signal was detected by AE sensors of $60 \mathrm{kHz}$ resonance frequency at $1 \mathrm{MHz}$. The arrival times of waveforms were determined by AIC (Akaike information criteria) method [Ohno and Ohtsu 2008]. 


\section{RESULTS AND DISCUSSIONS}

Results of Wheel Load Running Test with AE Monitoring. Figure 6 shows the delamination area between concrete and BP at the bottom of the specimen. The delamination area was determined by hammering test at bottom of the specimen. The delamination started to occur at edges of the specimen at initial loading within 10 thousands cycles. After that, the delamination area increased with increasing load cycle. Finally, BP completely separated from concrete at 500 thousands cycles. Figure 7 illustrates observed cracks at upper surface of concrete. The visual inspection is usually conducted at bottom of the $\mathrm{RC}$ slab, while the surface concrete at the bottom in this specimen could not see because the concrete surface at the bottom was covered by BP. Therefore, status of the concrete was observed from top of the specimen. Surface cracks were observed from 300 thousands cycles, crack density increased with increasing loading cycle. Here, the upper surface of the concrete kept flat plane, aggregate did not appear at the upper surface until 700 thousands cycles corresponding to end of the experiment.
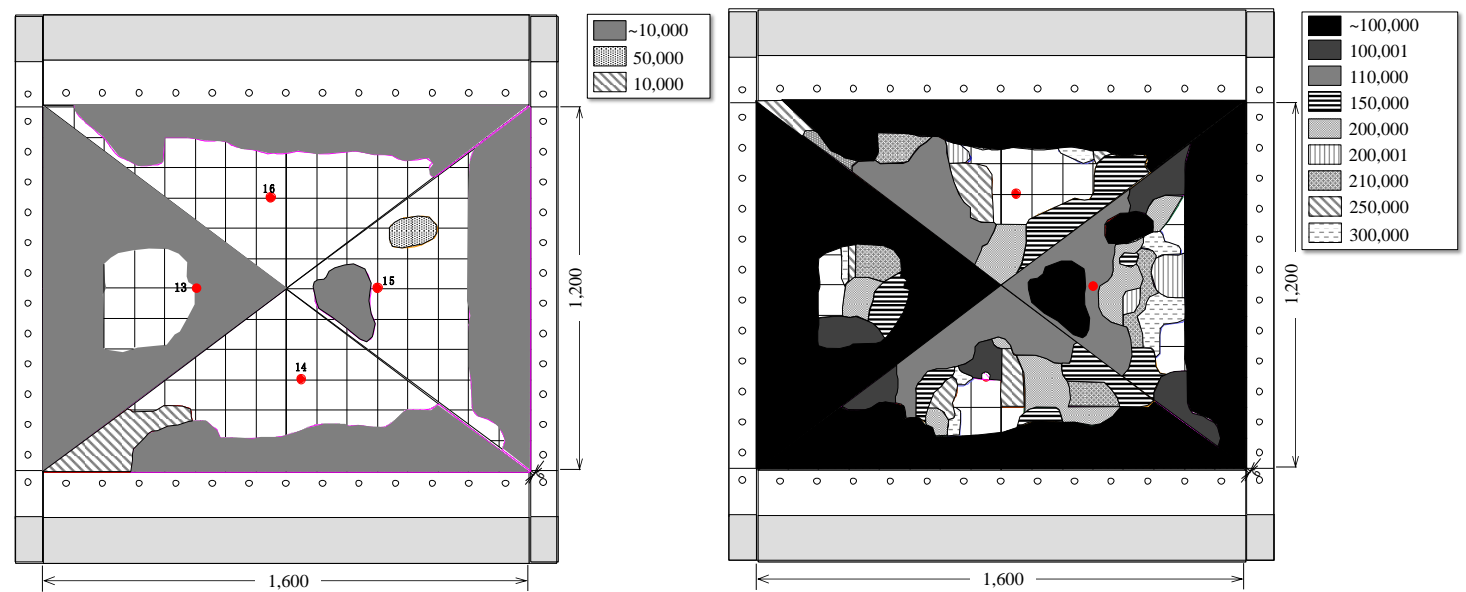

(a) 100,000 cycles

(b) $100,000 \sim 300,000$ cycles

Figure 6. Delamination area between concrete and BP

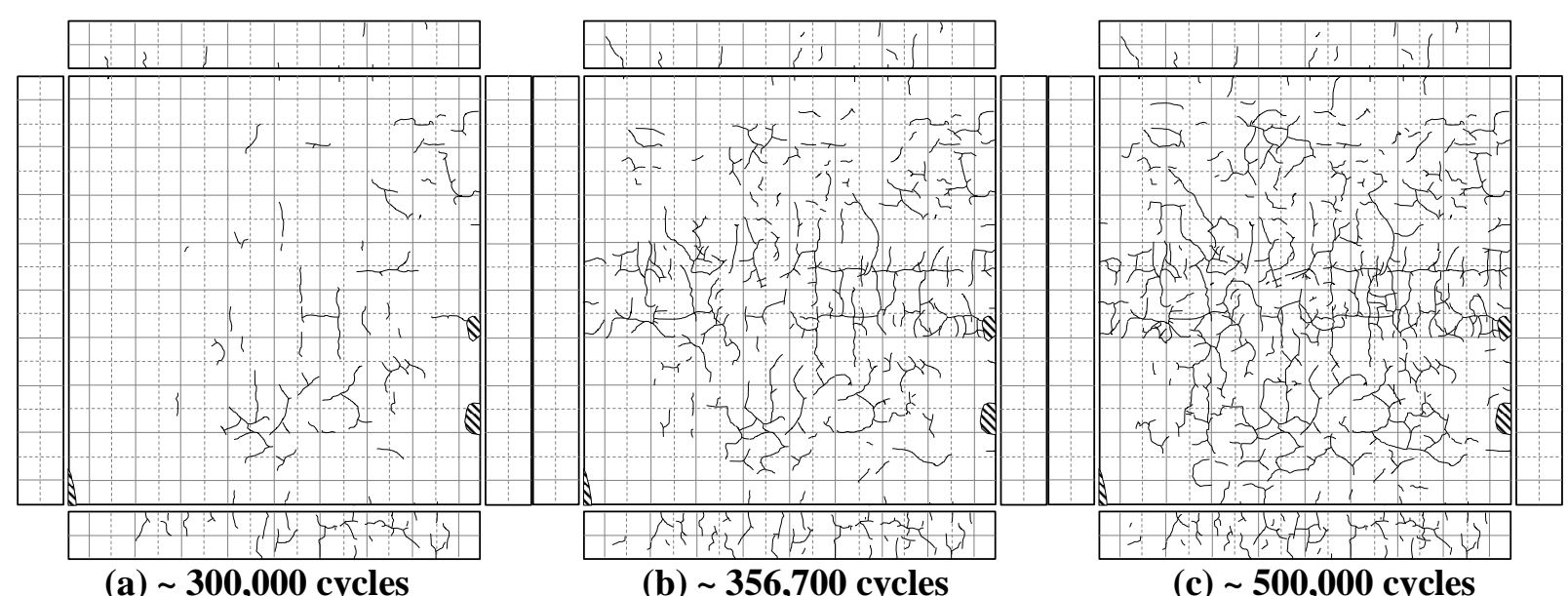

Figure 7. Observed cracks at upper surface of concrete 
Figure 8 shows the deflection of the specimen. The deflection of the specimen became constant value until 100 thousands cycles, this phenomena shows elastic behavior of the specimen. After increasing of the load level from 100,001 cycles, the deflection gradually increased as increasing loading cycles. The form of the deflection indicated "W shape" observed after 300 thousands cycles. This shape suggests that cracks related with punching shear failure generate in concrete. The biggest deflection occurred at 450 thousand cycles, after that deflection did not change despite increasing of loading cycle.

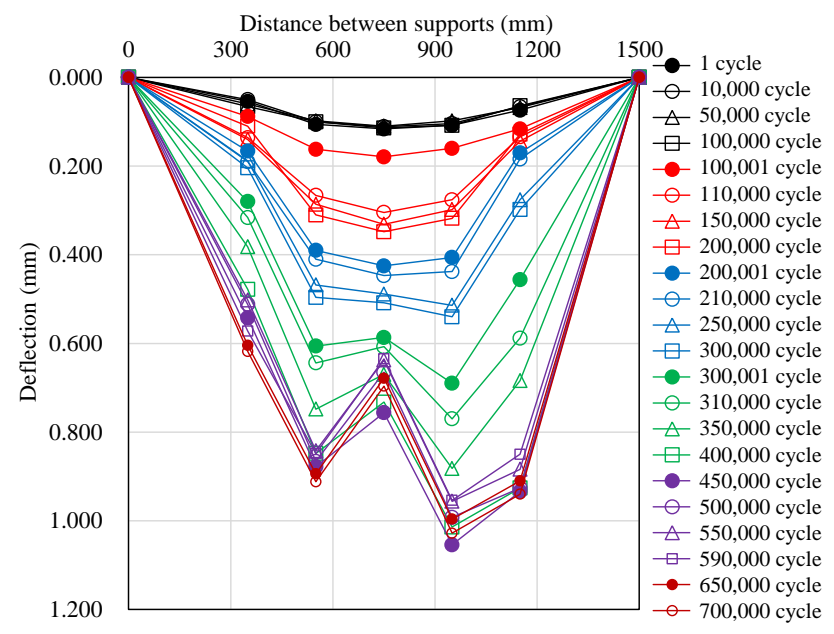

Figure 8. The deflection of the specimen

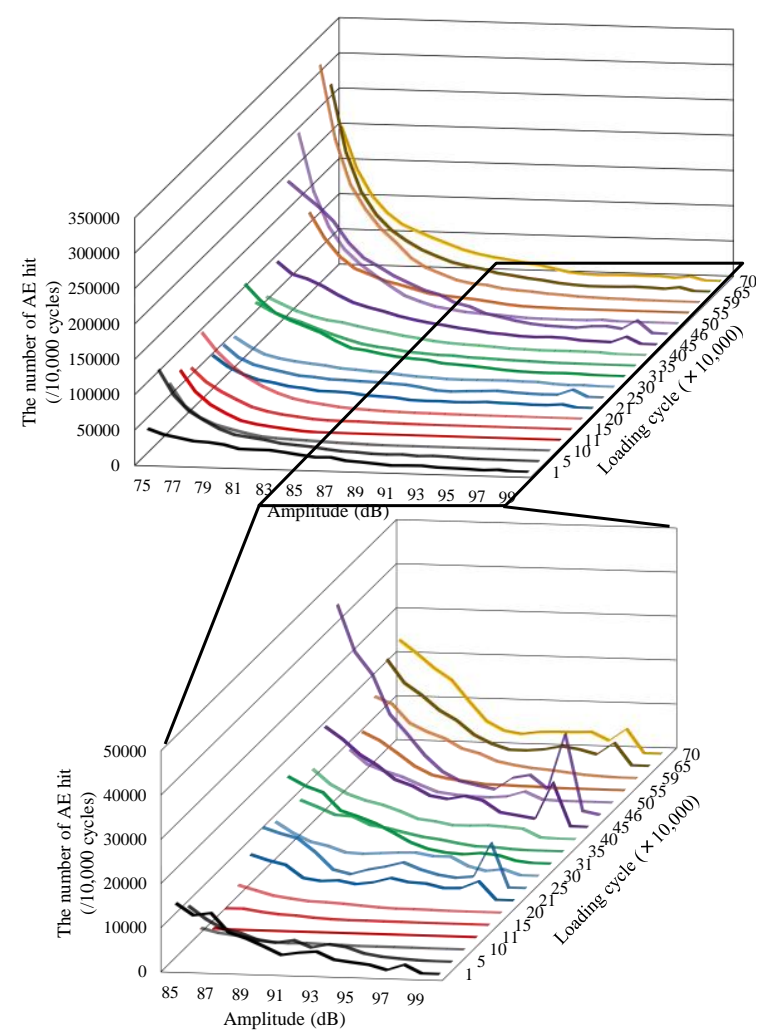

(a) Concrete

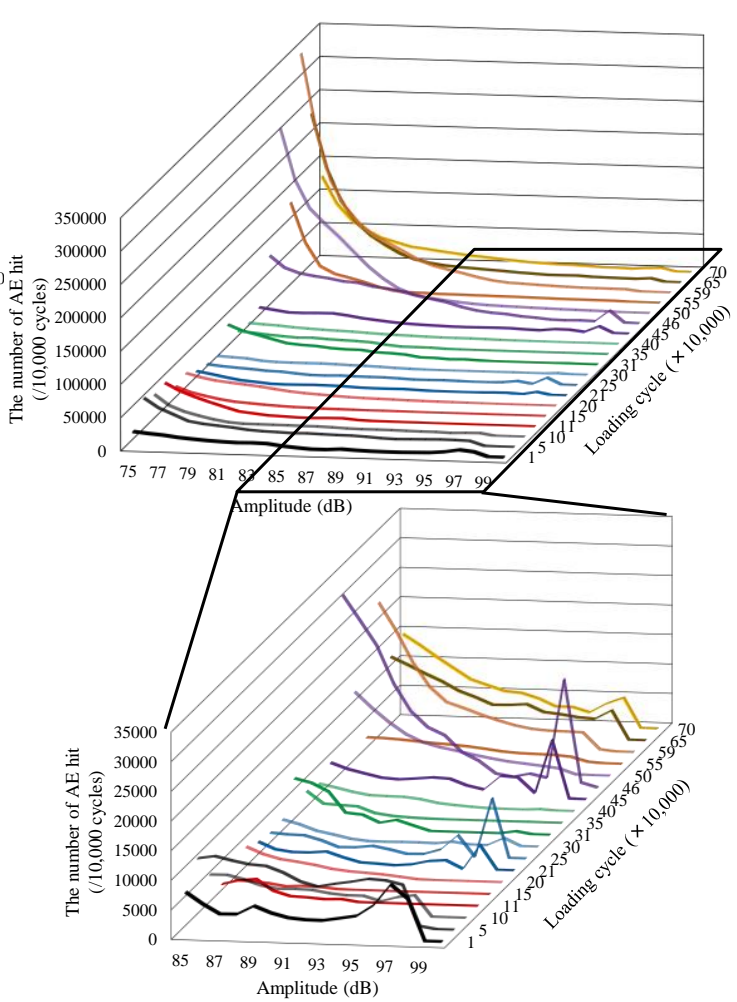

(b) BP

Figure 9. The number of AE hit during wheel load running 
$\mathrm{AE}$ monitoring was conducted during wheel load running test, the numbers of $\mathrm{AE}$ hits per 10 thousands cycles are summarized in Figure 9. The numbers of AE hits increased after 450 thousands cycles at sensors attached to both concrete and BP. Focusing on AE signals larger than $85 \mathrm{~dB}$, the numbers of AE hits detected at BP were large at 10 and 50 thousand loading cycles. These signals were associated with delamination between concrete and BP as shown in Figure 6. At 210 and 250 thousands cycles, AE hits had high amplitude obtained from both sensors attached concrete and BP again. Then, the numbers of AE hits decreased at next cycles. After that, a large number of AE hits were detected at 450 thousands cycles. In this time, since the biggest deflection occurred as shown in Figure 8, it is suggested that AE generation behavior corresponds to failure process in the specimen.

Figure 10 shows results of the AE source location during wheel load running test. AE sources lower than $84 \mathrm{~dB}$ widely distributed in the specimen, while AE sources higher than $85 \mathrm{~dB}$ relatively concentrated at bottom of the specimen at 100 thousand cycles. These higher AE sources generated due to delamination between concrete and BP at initial loading cycles. The number of AE sources decreased from 100 to 300 thousands cycles, AE sources localized at limited area. This phenomenon thought that these AE sources related with cracks corresponding to punching shear failure. AE sources widely re-plotted in the specimen from 400 to 500 thousands cycles. In this time, fatigue damage accumulated in concrete.
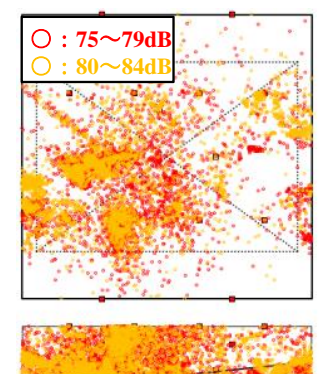

\section{(a) $\sim 100,000$ cycles}
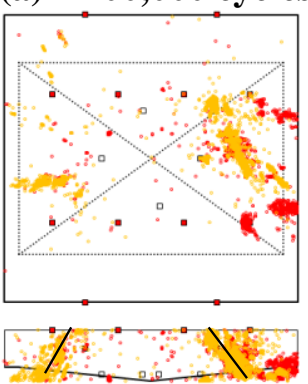

(c) $200,000 \sim 300,000$ cycles
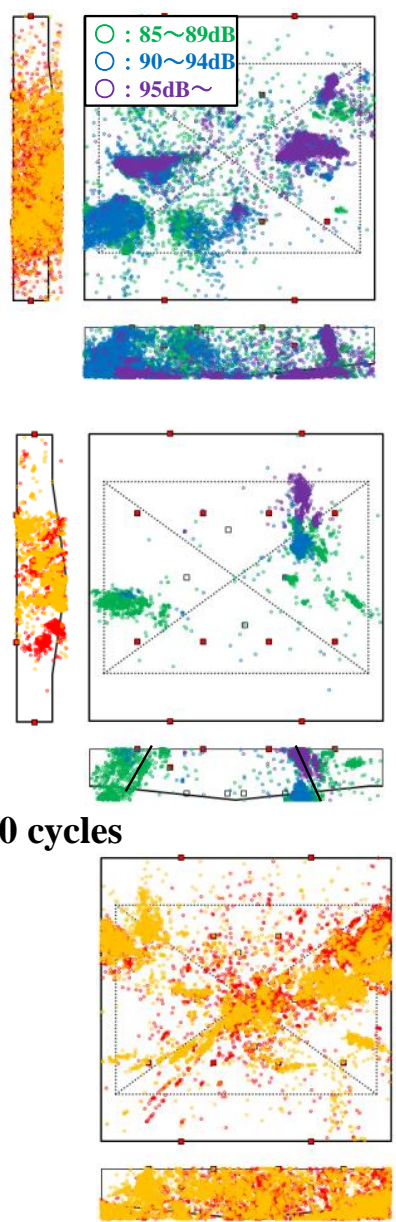
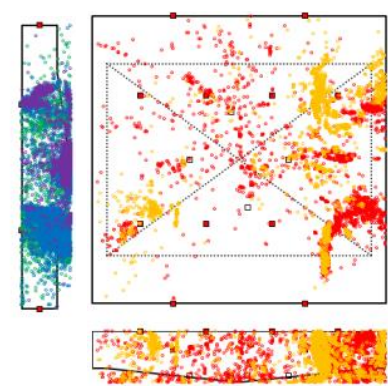

(b) $100,000 \sim 200,000$ cycles

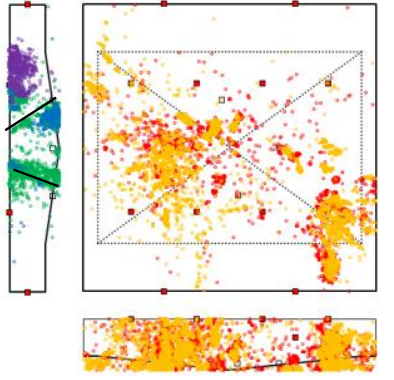

(d) $300,000 \sim 400,000$ cycles

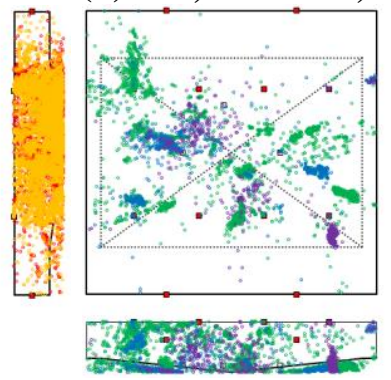

A
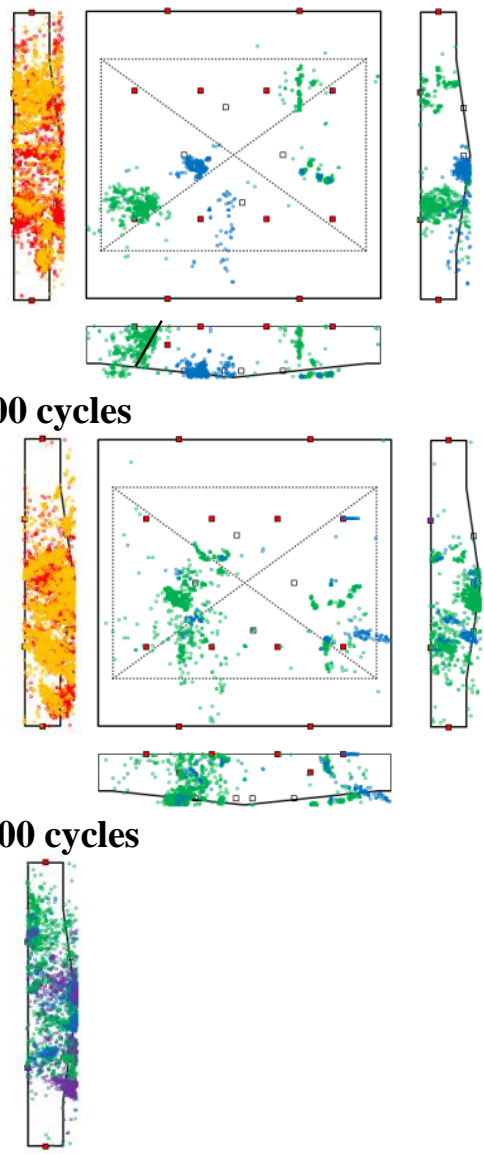

(e) 400,000 500,000 cycles

Figure 10. Results of AE source location during wheel running test 
Results of Impact Elastic Wave method. In this study, travel time tomography of elastic wave was applied to investigate damage degree of concrete in the specimen. In the travel time tomography, monitoring area was divided into small triangle cells at first. In the tomography method, the velocity in concrete is homogeneous and isotropic in each cell. Slowness is defined as the reciprocal of velocity. The relation between the observed travel time of the $j$ th ray, $T_{j}$, and the slowness of the $i$ th cell, $S_{i}$, is given by the following equation [Watanabe and Sassa 1996],

$$
T_{i}=\sum_{i} l_{i j} S_{i}
$$

where $l_{i j}$ is the length of the ray path of the $j$ th ray in the $i$ th cell.

The procedure of travel time tomography is shown in Figure 11. In model modification, the initial model was modified by the simultaneous iterative reconstruction technique (SIRT) method, the number of modification was set to 100 cycles, then result got when the discrepancy between observed and theoretical value became smallest value.

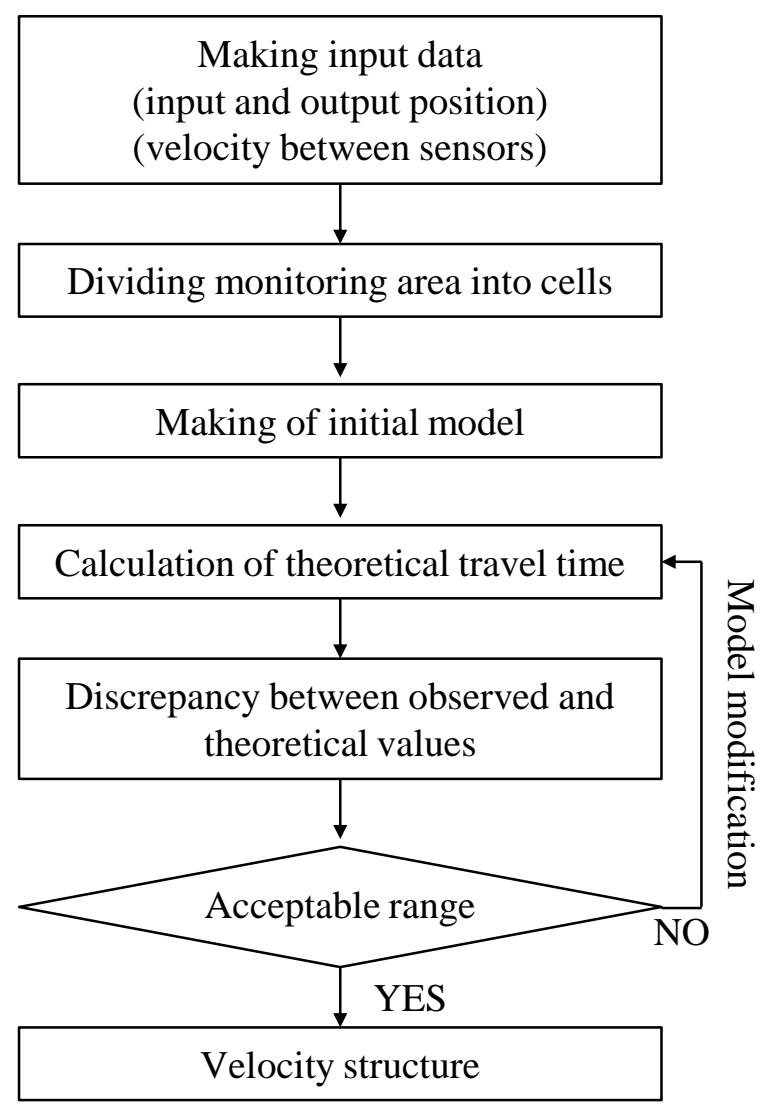

\section{Figure 11. Procedure of travel time tomography}

Figure 12 summarizes the results of the travel time tomography. Wave velocity in concrete did not change from initial to 210 thousands cycles. And then, wave velocity at loading area of the specimen decreased at 250 thousands cycles. At this moment, the deflection of the specimen started to slightly form $\mathrm{W}$ shape, it is thought that fatigue damage of concrete would be accumulated. After that, cracks were observed at upper surface of the concrete at 300 thousands cycles. Therefore, deterioration of concrete due to fatigue could be estimated by impact elastic wave method before cracks occur at concrete surface. The wave velocity gradually decreased from 400 to 450 cycles, lower velocity area spread from loading area to sides of the specimen. 


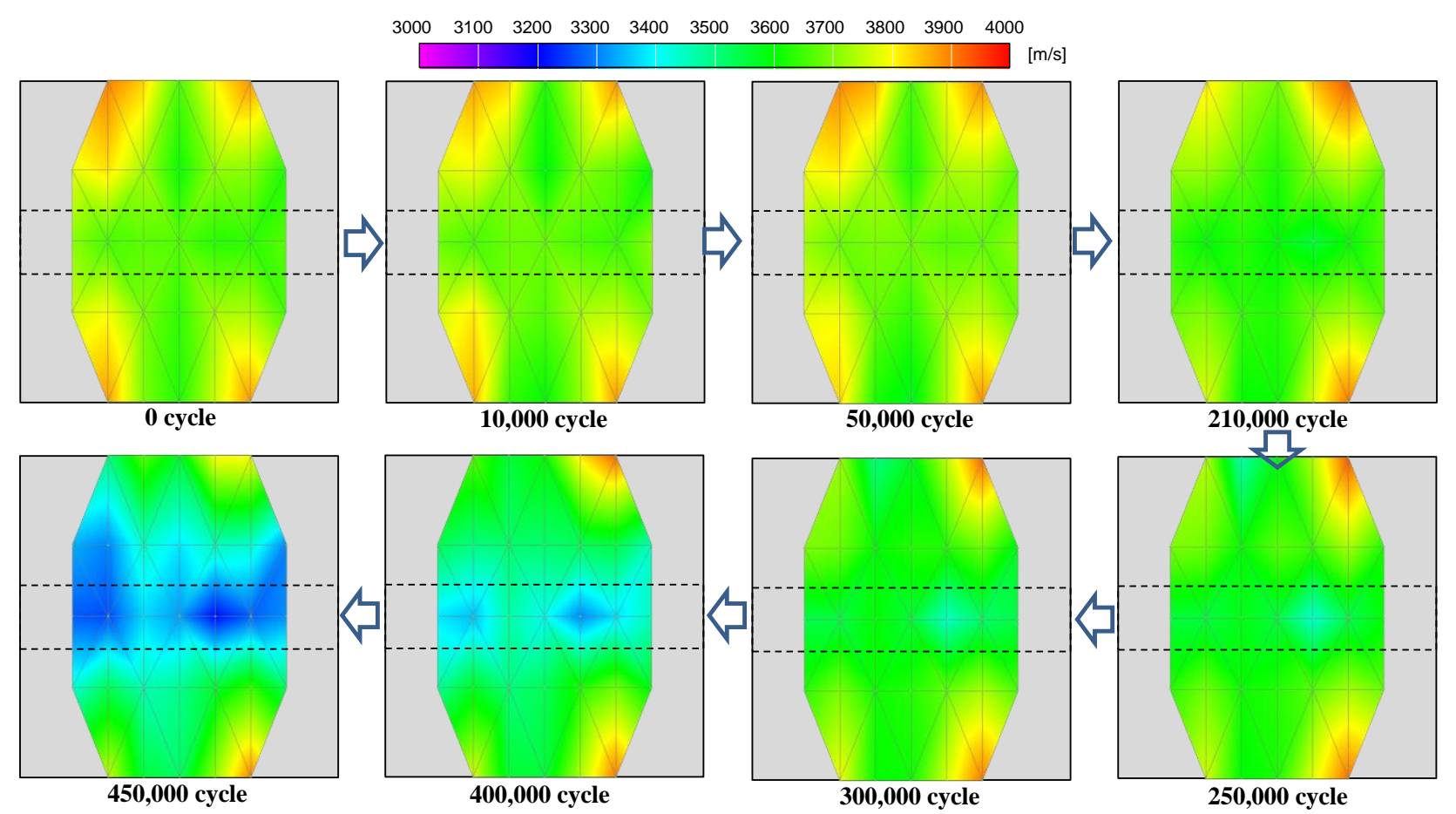

Figure 12. Results of the travel time tomography

\section{CONCLUSION}

In this study, wheel load running test was conducted to a real-size BP slab specimen to investigate fatigue process by means of $\mathrm{AE}$ and impact elastic wave. Conclusions can be drawn as follows:

- The delamination between concrete and BP generated from edges of the specimen at early loading cycles, and then the delamination area extended from edges to center of the specimen. Concrete and BP were eventually separated at 500 thousand cycles, while loading capacity did not decrease until 700 thousands cycles corresponding to end of the experiment. This is because BP connected with girder in this specimen, it is suggested that BP slab has high durability for traffic load.

- AE signals had relatively lower amplitude widely spread in the specimen, while higher amplitude signals were detected at bottom of the specimen at early cycles. These higher amplitude signals were due to delamination between concrete and BP. In addition, AE sources corresponding to cracks due to punching shear failure were detected with increasing of loading cycles. It is suggested that $\mathrm{AE}$ monitoring is useful tool for health monitoring of BP slab.

- The state of concrete in BP slab can be estimated by the travel time tomography. The damage area is visualized by changing of wave velocity in concrete of the specimen.

\section{REFERENCES}

Aggelis, G.D., Mpalaskas, C.A., and Matikas, E.T. (2013). "Investigation of Different Fracture Modes in Cement-based Materials by Acoustic Emission." Cement and Concrete Research, 48, 1-8.

Behnia, A, Chai, K. H. and Shiotani, T. (2014). "Advanced Structural Health Monitoring of Concrete Structures with aid of Acoustic Emission." Construction and Building Materials, 65, 282-302. 
Liu, F.K., Chai, K.H., Mehrabi, N., Kobayashi, Y. and Shiotani, T. (2014). "Condition Assessment of PC Tendon Duct filling by Elastic Wave Velocity Mapping." The Scientific World Journal, 24, Article ID 194295, 14 pages.

Nair, A and Cai, .S.C. (2010). "Acoustic Emission Monitoring of Bridges: Review and Case Studies." Engineering Structures, 32, 1704-1714.

Ohno, K. and Ohtsu, M. (2008). "Mechanisms of Concrete Fracture analyzed by AE-SiGMA with Automatic Detector of First Motion." Proceedings of International Conference on Fracture 2008, in CD-ROM.

Ohno, K. and Ohtsu, M. (2010). "Crack Classification in Concrete based on Acoustic Emission." Construction and Building Materials, 24, 2339-2346.

Ohtsu, M. (1995). "The History and Development of Acoustic Emission in Concrete Engineering." Concrete Library of JSCE, No.25, 121-134.

Ohtsu, M. (2010). "Recommendation of RILEM TC 212-ACD: Acoustic Emission and Related NDE Techniques for Crack Detection and Damage Evaluation in Concrete, Test Method for Classification of Active Cracks in Concrete Structures by Acoustic Emission." Materials and Structures, 43, 11871189.

Japan Society of Civil Engineering (2010), "Standard Specification for Concrete Structures - 2007." 215232

Shiotani, T., Momoki, S., Chai, H. and Aggelis D.G. (2009). "Elastic Wave Validation of Large Concrete Structures repaired by means of Cement Grouting." Construction and Building Materials, 23, 26472652.

Watanabe, T. and Sassa, K. (1996). "Seismic Attenuation Tomography and its Application to Rock Mass Evaluation." International Journal of Rock Mechanics and Mining Sciences \& Geomechanics Abstracts, 33, 467-477. 